\title{
Tráfico humano
}

\author{
Tráfico humano \\ Human trafficking
}

\begin{abstract}
RESUMO
A pesquisa trata das questões relativas ao tráfico internacional de pessoas, o qual tem sido uma preocupação mundial com relação a sua repressão e prevenção. O fato é que o fenômeno se apresenta com considerável aumento gradativo, resultado de contradições políticas e sociais que foram acentuadas pela globalização e o avanço tecnológico, bem como pelas lacunas deixadas na fiscalização e pela corrupção fronteiriça dos Estados-Nações. Assim, tanto o tráfico humano para fins de exploração sexual como para a prática do trabalho escravo vem sofrendo um agravamento, tendo como principal causa a desigualdade social e cultural dos povos.
\end{abstract}

\section{PALAVRAS-CHAVE}

Pessoas, Tráfico internacional, Exploração sexual, Trabalho escravo.

\section{RESUMEN}

La investigación se ocupa de cuestiones relativas a la trata internacional de personas, lo que ha sido motivo de preocupación en todo el mundo acerca de su enjuiciamiento y la prevención. El hecho es que el fenómeno se presenta, con un considerable aumento gradual como resultado, de las contradicciones políticas y sociales que fueron acentuadas por la globalización y los avances tecnológicos, así como las lagunas existentes, en la aplicación y la frontera corrupción de los Estados-nación. Así, tanto la trata de personas, con fines de explotación sexual y de la práctica del trabajo esclavo, ha sufrido un aumento con la principal causa la desigualdad social y cultural de los pueblos.

\section{PALABRAS CLAVE}

Las personas, Tráfico internacional, Explotación sexual, Trabajo forzado.

\section{ABSTRACT}

The research deals with issues relating to international trafficking in persons, which has been a worldwide concern about his prosecution and prevention. The fact is that the phenomenon presents with considerable increase gradually as a result of political and social contradictions that were accentuated by globalization and technological advances, as well as the gaps left in enforcement and border corruption of nation states. Thus, both human trafficking for sexual exploitation and to the practice of slave labor has suffered an aggravation, with the main causes social and cultural inequality of peoples.

\section{KEYWORDS}

People, International trafficking, Sexual exploitation, Forced labor.

\section{NEREIDE JORGE PEREIRA ESPÍNDOLA}

Possui graduação em Pedagogia pelo Centro Universitário do Triângulo (1996). Possui Pós-graduação em Redes de Computadores pela Universidade Federal de Uberlândia (2002). Possui graduação em DIREITO pela Universidade de Uberaba (2010). Possui Pós- graduação em Direito de Empresa pela Universidade Federal de Uberlândia 2012-2013. Atualmente é professora, advogada e conciliadora do TJMG. nereidejorge@hotmail.com 
INTRODUÇÃO

A pesquisa visa abordara a problemática do tráfico internacional de pessoas e suas implicações relativas à preocupação da comunidade mundial. Sendo que a principal função dos Estados é garantir a proteção aos direitos fundamentais do indivíduo, certos princípios elencados tanto na Constituição Federal quanto nos instrumentos internacionais devem ser observados e explanados na pesquisa.

Uma vez que a segurança e a liberdade dos indivíduos sempre foram questões de grande preocupação das comunidades internacionais, bem como da comunidade jurídica brasileira. Sendo assim, se faz relevante a abordagem da dignidade da pessoa humana e dos direitos humanos, os quais consistem nos primeiros princípios a serem violados com a prática do tráfico internacional de pessoas. No âmbito da legislação brasileira destaca-se a aplicação dos comandos do Código Penal brasileiro no combate a tal ilícito penal.

O objetivo específico da pesquisa é abordar o tráfico internacional de pessoas sua incidência e a legislação pertinente à repressão do mesmo, tanto em nível nacional quanto internacional.

Os objetivos específicos consistem em discorrer a respeito do princípio da dignidade da pessoa humana; analisar os instrumentos relativos à proteção aos direitos humanos; ressaltar a importância dos instrumentos internacionais de proteção e prevenção ao tráfico de pessoas; demonstrar a repressão ao tráfico internacional de seres humanos na legislação brasileira; tecer considerações a respeito do tráfico internacional para a exploração sexual e para o trabalho escravo; observar as dificuldades na detecção do crime de tráfico de pessoas, entre outras questões relevantes.

A metodologia a ser utilizada na pesquisa funda-se na pesquisa bibliográfica, cujas fontes consultadas tiveram por objetivo estudar e investigar previamente questões relevantes a respeito do tráfico internacional de pessoas. Sendo assim, o teve por base o amplo leque de fontes disponível em periódicos, em artigos da internet, na legislação pátria, entre outros que trazem informações e reflexões sobre o assunto. Foi realizado um levantamento dos materiais disponíveis, os quais foram fichados um a um após uma leitura cuidadosa dos mesmos a fim de compor um conjunto de informações selecionadas e classificadas de acordo com as exigências que o tema requer que ficaram pré-definidas e nortearam o estudo.

\section{O PRINCÍPIO DA DIGNIDADE DA PESSOA HUMANA}

O próprio Estado Democrático de Direito garante a dignidade da pessoa humana. Por esse motivo, no Brasil, esse princípio foi inserido pelo legislador constituinte logo no artigo 1ํ, III da Constituição Federal de 1988 
recebendo, desta forma, a condição de cláusula pétrea. Assim dispõe o mencionado dispositivo: "Art. 1ㅇ - A República Federativa do Brasil, formada pela união indissolúvel dos Estados e Municípios e do Distrito Federal, constitui-se em Estado Democrático de Direito e tem como fundamentos: III - a dignidade da pessoa humana". Esse dispositivo é um dos fundamentos da República Federativa do Brasil, portanto, deve ser considerado como um dos pilares do Estado Democrático de Direito. Vicente Paulo e Marcelo Alexandrino a respeito do referido princípio explicam que:

A dignidade da pessoa humana como fundamento da República Federativa do Brasil consagra, desde logo, nosso Estado como uma organização centrada no ser humano, e não em qualquer outro referencial. A razão de ser do Estado Brasileiro não se funda na propriedade, em classes, em corporações, em organizações religiosas, tampouco no próprio Estado (como ocorre nos regimes totalitários), mas sim na pessoa humana (Vicente, 2010, p. 90).

Por tanto, qualquer prática que atente contra a dignidade da pessoa humana é condenável. Alexandre de Moraes afirma que:

A dignidade da pessoa humana é um valor espiritual e moral inerente à pessoa, que se manifesta singularmente na autodeterminação consciente e responsável da própria vida e que traz a pretensão ao respeito por parte das demais pessoas, constituindo-se em um mínimo invulnerável que todo estatuto jurídico deve assegurar, de modo que apenas excepcionalmente possam ser feitas limitações ao exercício dos direitos fundamentais, mas sempre sem menosprezar a necessária estima que merecem todas as pessoas enquanto seres humanos (Moraes, 2003, p. 128).

Ingo Wolfgang Sarlet lembra que a dignidade da pessoa humana "é decorrente da própria condição humana. (...) é a qualidade intrínseca e distintiva reconhecida em cada ser humano que o faz merecedor do mesmo respeito e consideração por parte do Estado e da comunidade" (Sarlet, 2006, pp. 64-65).

Maria Helena Diniz defende que o princípio da dignidade da pessoa humana consiste na base da comunidade familiar promovendo seu pleno desenvolvimento e a realização de todos os seus membros, em especial da criança e do adolescente, e faz críticas a juristas que, diante do novo conceito de família, comenta a crise, a desagregação e o desprestígio. Observa ainda que não há dúvidas de que a família passa por grandes modificações, porém, como organismo natural, ela não se extingue e como organismo jurídico vem se transformando em uma nova organização (Diniz, 2005, p. 198).

Assim, a dignidade da pessoa humana está inserida nos direitos e garantias fundamentais, sendo, portanto, inerente à personalidade humana. A dignidade é uma valoração moral da pessoa, cuja pretensão consiste no respeito por parte das demais pessoas. 
Nos dizeres de Thomas Fleiner: "Os ataques contra a dignidade humana não se limitam à utilização de técnicas sutis e sofisticadas (...)" (Fleiner, 2003, p. 11).

Vale observar que a dignidade da pessoa humana é o alicerce para todos os direitos que a Constituição Federal assegura ao indivíduo, seja aqueles relativos à liberdade, os políticos, os do trabalho e os sociais, que fazem parte de todas as constituições democráticas.

Ressalte-se que o autor desenvolve a fórmula de dignidade a partir do conceito de Düring, com base na concepção Kantiana, a qual considera que a dignidade é atingida quando o indivíduo for rebaixado a objeto, tratado como coisa, desconsiderado como sujeito de direitos. Alerta também para o fato de que alguns países também inseriram no texto constitucional o princípio da dignidade, entre os quais: Alemanha, Espanha, Grécia, Irlanda, Portugal, Itália, Bélgica, Paraguai, Cuba, Venezuela, Peru, Bolívia, Chile, Guatemala e Rússia (Sarlet, 2006, p. 65).

Para Immanuel Kant:

(...) a dignidade é o valor de que se reveste tudo aquilo que não tem preço, ou seja, não é passível de ser substituído por um equivalente. (...) a dignidade é totalmente inseparável da autonomia para o exercício da razão prática, e é por esse motivo que apenas os seres humanos revestem-se de dignidade (Kant, 2004, p. 52).
Atualmente as legislações conseguiram grandes avanços em termos de direitos humanos. No Brasil o direito interno incorporou o conteúdo de vários instrumentos internacionais existentes, além de ser signatário desses instrumentos. Entretanto, alguns desses avanços ainda aguardam por ser materializados na prática. Sem dúvida que a dignidade no trato com o ser humano é um direito inerente a todos os indivíduos, mas nos presídios isso nem sempre ocorre e os problemas estão aí, se tornam cada vez maiores. Existem ideias a respeito do que possa ser feito para transformar a situação, mas nada é colocado em prática de maneira efetiva.

Lauro Cesar Mazetto Ferreira considera que: "a dignidade da pessoa, fundamento de nosso sistema jurídico, é o ponto-chave do reconhecimento e proteção dos direitos humanos. É o fim último que garante um patamar de direitos que seja capaz de preservar seu objetivo fundamental" (Ferreira, 2007, p. 195).

\section{OS DIREITOS HUMANOS}

É imprescindível a concretização dos Documentos Internacionais que elevam os direitos fundamentais do homem, para fazer valer os princípios e regras de valor universal, uma vez que o ser humano é o único que pode dar conteúdo moral aos seus atos, bem como é o único que pode exercer eticamente suas ações.

A Declaração Americana dos Direitos e De- 
veres do Homem, aprovada no ano de 1948, historicamente, foi o acordo internacional pioneiro que versou a respeito dos direitos humanos, pois antecedeu à Declaração Universal dos Direitos Humanos, que foi promulgada seis meses depois.

Já em seu Preâmbulo a mencionada Declaração afirma que:

Todos os homens nascem livres e iguais em dignidade e direitos e, como são dotados pela natureza de razão e consciência, devem proceder fraternalmente uns para com os outros. (...) o cumprimento do dever de cada um é exigência do direito de todos. Direitos e deveres integram-se correlativamente em toda a atividade social e política do homem. Se os direitos exaltam a liberdade individual, os deveres exprimem a dignidade dessa liberdade.

Essa abrangência em relação a tais direitos traz a ideia de que os direitos humanos são universais, não importando a nacionalidade do indivíduo, apenas considerando requisitos mínimos para que a pessoa seja titular de direitos, evocando, para tanto, a aplicação do princípio dignidade humana.

Porém, os costumes de cada cultura é que forma a fonte dos direitos humanos. Tendo em sua fundamentação as limitações advindas de valores culturais próprios. Então, pode-se afirmar que o ser humano é produto do meio. Conforme observa Flávia Piovesan:
Neste prisma, cada cultura possui seu próprio discurso acerca dos direitos fundamentais, que está relacionado às específicas circunstâncias culturais e históricas de cada sociedade. Neste sentido, acreditam os relativistas, o pluralismo cultural impede a formação de uma moral universal, tornando-se necessário que se respeite as diferenças culturais apresentadas por cada sociedade, bem como seu peculiar sistema moral (Piovesan, 2002, pp. 192193).

Seja qual for o tipo de crença ou convicção, a vida é considerada para todos os povos como um valor ético e, na convivência obrigatória com outros seres humanos, cada um deve respeito à dignidade do outro.

Foram os atos desumanos praticados especialmente contra aos judeus que deram origem à constitucionalização da dignidade da pessoa humana, positivando-a na maioria das constituições ocidentais e na Declaração Universal das Nações Unidas, de 10 de dezembro de 1948. Portanto, de acordo com Flávia Piovesan, pode-se observar que foi a experiência nazista que gerou a necessidade da preservação da dignidade da pessoa humana (Piovesan, 2005, p. 48).

A mencionada autora ainda afirma que "a Declaração Universal de 1948, ao apresentar a concepção contemporânea de direitos humanos, acolhe a dignidade humana como valor a iluminar o universo dos direitos". E ainda, que a titularidade de direitos tem como 
único requisito a condição humana, considerando-se que todo ser humano tem uma dignidade a ele inerente, não estando esta na dependência de qualquer outro critério, senão o de ser humano. "O valor da dignidade humana projeta-se, portanto, por todo o sistema de proteção" (Piovesan, 2005, p. 43).

Sendo assim, o efetivo reconhecimento da dignidade da pessoa humana é uma das grandes conquistas do homem na cultura moderna. Cabendo ressaltar que a Declaração Universal dos Direitos Humanos é a própria expressão da consciência da humanidade sobre a dignidade da pessoa humana.

O ser humano, por sua própria natureza, prima por uma vida com dignidade com a presença da ética em todas as sociedades humanas.

\section{DOS INSTRUMENTOS INTERNACIONAIS DE PROTEÇÃO}

Dentre os vários instrumentos internacionais que existem na seara dos direitos humanos, destacam-se alguns deles.

\subsection{A Declaração Americana dos Direitos e Deveres do Homem (10-04-1948)}

Aprovada no ano de 1948, historicamente, foi o acordo internacional pioneiro que versou a respeito dos direitos humanos, pois antecedeu à Declaração Universal dos Direitos Humanos, que foi promulgada seis meses depois.
Já em seu Preâmbulo a mencionada Declaração afirma que "Todos os homens nascem livres e iguais em dignidade e direitos (...)". Nos seus artigos I e II reafirma esses direitos:

Artigo I - Todo ser humano tem direito à vida, à liberdade e à segurança de sua pessoa.

Artigo II - Todas as pessoas são iguais perante a lei e têm os direitos e deveres consagrados nesta Declaração, sem distinção de raça, língua, crença ou qualquer outra.

Equiparando-se à Declaração anteriormente citada configura-se um documento de princípios, o qual deve ser observado em sua íntegra. Foi instituída como forma de reiterar e fortalecer o disposto na Declaração Universal.

\subsection{A Declaração Universal dos Direitos do Homem (10-12-1948)}

Esta Declaração inovou em relação a ter aliado o rol dos direitos civis e políticos ao dos direitos sociais, econômicos e culturais, dando uma conotação e linguagem renovada aos direitos humanos. Deixou claro também que a igualdade e a liberdade são direitos indissociáveis.

Os artigos 1 e 2 dessa Declaração Universal diz respeito aos direitos mais fundamentais do homem:

Artigo 1. Todos os homens nascem livres e iguais em dignidade e direitos. São do- 
tados de razão e consciência e devem agir em relação uns aos outros com espírito de fraternidade.

Artigo 2. I) Todo o homem tem capacidade para gozar os direitos e as liberdades estabelecidos nesta Declaração sem distinção de qualquer espécie, seja de raça, cor, sexo, língua, religião, opinião política ou de outra natureza, origem nacional ou social, riqueza, nascimento, ou qualquer outra condição.

Assim, a Declaração consolida a natureza indivisível dos direitos que nela estão previstos, bem como ressalta seu caráter universal. Orienta também que devem ser observados os direitos, independentemente, da diversidade cultural, política, econômica e religiosa das sociedades. Enfim, primou-se pela reconstrução do valor dos direitos humanos como referencial ético da ordem internacional, o que veio constituir a fundamentação de todos os documentos posteriores relativos aos direitos humanos.

\subsection{A Convenção Americana sobre Direitos Humanos (22-11-1969)}

Esta Convenção é conhecida como "Pacto de San José da Costa Rica", local onde aconteceu o encontro. Foi proclamada pela Resolução 217 A (III) da Assembléia Geral das Nações Unidas, de 10 de dezembro de 1948, e na mesma estão inseridos: o direito à liberdade pessoal, a proteção da honra e da dignidade e a igualdade perante a lei.
Os itens 1 e 2 do seu artigo 1 으 impõem o respeito aos diretos:

Artigo 1ㅇ- Obrigação de respeitar os direitos.

1. Os Estados Partes nesta Convenção comprometem-se a respeitar os direitos e liberdades nela reconhecidos e a garantir seu livre e pleno exercício a toda pessoa que esteja sujeita a sua jurisdição, sem discriminação alguma por motivo de raça, cor, sexo, idioma, religião, opiniões políticas ou de qualquer outra natureza, origem nacional ou social, posição econômica, nascimento ou qualquer outra condição social.

2. Para os efeitos desta Convenção, pessoa é todo ser humano.

Nessa Convenção conhecida como Pacto de San José da Costa Rica, os direitos humanos estão implicitamente consolidados.

\section{O TRÁFICO INTERNACIONAL DE SERES HUMANOS NA LEGISLAÇÃO BRASILEIRA}

A Convenção das Nações Unidas contra o Crime Organizado Transnacional, a qual foi implementada no sistema jurídico brasileiro através do Decreto no 5.015/2004, significou importante avanço no combate ao crime organizado. Posteriormente, o Decreto no 5.017/2004, por sua vez, internalizou o Protocolo Adicional à Convenção das Nações Unidas contra o Crime Organizado Transnacional Relativo à Prevenção, Repressão e Punição do Tráfico de Pessoas, em Especial 
Mulheres e Crianças, em seu artigo 3, alínea "a" determina que:

Artigo 3. Definições.

Para efeitos do presente Protocolo:

a) A expressão "tráfico de pessoas" significa o recrutamento, o transporte, a transferência, o alojamento ou o acolhimento de pessoas, recorrendo à ameaça ou uso da força ou a outras formas de coação, ao rapto, à fraude, ao engano, ao abuso de autoridade ou à situação de vulnerabilidade ou à entrega ou aceitação de pagamentos ou benefícios para obter o consentimento de uma pessoa que tenha autoridade sobre outra para fins de exploração. A exploração incluirá, no mínimo, a exploração da prostituição de outrem ou outras formas de exploração sexual, o trabalho ou serviços forçados, escravatura ou práticas similares à escravatura, a servidão ou a remoção de órgãos.

O mencionado Protocolo Adicional definiu certas obrigações a serem observadas pelos países signatários e, entre outras exigências, determinou a criação de uma estrutura normativa e de políticas públicas com relação à prevenção e repressão ao tráfico internacional de seres humanos.

A Lei $\mathrm{n}$ - 12.015, de 7 de agosto de 2009 veio inovar quanto aos crimes contra a dignidade sexual, o lenocínio e o tráfico de pessoa com finalidade de prostituição ou qualquer es- pécie de exploração sexual, contudo, trouxe consideráveis alterações.

Nesse sentido, o Código Penal brasileiro também sofreu alterações com a edição da Lei no 12.015/2009 que modificou o seu artigo 231 do mencionado Diploma, o qual dispõe a respeito do tráfico internacional de pessoa para fim de exploração sexual:

Art. 231. Promover ou facilitar a entrada, no território nacional, de alguém que nele venha a exercer a prostituição ou outra forma de exploração sexual, ou a saída de alguém que vá exercê-la no estrangeiro. (Redação dada pela Lei № 12.015, de 2009).

Pena - reclusão, de 3 (três) a 8 (oito) anos. (Redação dada pela Lei no 12.015, de 2009).

$\S 1^{\circ}$ Incorre na mesma pena aquele que agenciar, aliciar ou comprar a pessoa traficada, assim como, tendo conhecimento dessa condição, transportá-la, transferi-la ou alojá-la. (Redação dada pela Lei no 12.015 , de 2009) (...).

Vale observar que o artigo 227, § 4ㅇda Constituição Federal e o artigo 239 do Estatuto da Criança e do Adolescente - ECA, assim determinam os citados Diplomas, respectivamente:

Art. 227. É dever da família, da sociedade e do Estado assegurar à criança, ao adolescente e ao jovem, com absoluta prioridade, o direito à vida, à saúde, à alimenta- 
ção, à educação, ao lazer, à profissionalização, à cultura, à dignidade, ao respeito, à liberdade e à convivência familiar e comunitária, além de colocá-los a salvo de toda forma de negligência, discriminação, exploração, violência, crueldade e opressão. (Redação dada Pela Emenda Constitucional $n=65$, de 2010)

\section{(...)}

$\S 4$ ㅇ - A lei punirá severamente o abuso, a violência e a exploração sexual da criança e do adolescente.

Art. 239. Promover ou auxiliar a efetivação de ato destinado ao envio de criança ou adolescente para o exterior com inobservância das formalidades legais ou com o fito de obter lucro:

Pena - reclusão de quatro a seis anos, e multa.

Parágrafo único. Se há emprego de violência, grave ameaça ou fraude: (Incluído pela Lei no 10.764, de 12.11.2003)

Pena - reclusão, de 6 (seis) a 8 (oito) anos, além da pena correspondente à violência.

Os mencionados dispositivos são os principais tipos penais para reprimir o tráfico internacional de pessoas e de crianças. Mas tem-se ainda a modalidade de escravidão no tráfico internacional de pessoas, cuja conduta é criminalizada no âmbito do artigo 149 do Código Penal, onde:

Art. 149. Reduzir alguém a condição análoga à de escravo, quer submetendo-o a trabalhos forçados ou a jornada exaustiva, quer sujeitando-o a condições degradantes de trabalho, quer restringindo, por qualquer meio, sua locomoção em razão de dívida contraída com o empregador ou preposto: (Redação dada pela Lei no 10.803, de 11.12.2003).

Pena - reclusão, de dois a oito anos, e multa, além da pena correspondente à violência. (Redação dada pela Lei no 10.803 , de 11.12.2003).

\section{(...)}

$\S 2^{\circ} \mathrm{A}$ pena é aumentada de metade, se o crime é cometido: (Incluído pela Lei no 10.803, de 11.12.2003).

I - contra criança ou adolescente; (Incluído pela Lei no 10.803 , de 11.12.2003).

Também com o intuito de prevenir e evitar o tráfico internacional de pessoas foi editado o Decreto no 5.948/2006, o qual aprovou "a Política Nacional de Enfrentamento ao Tráfico de Pessoas e institui Grupo de Trabalho Interministerial com o objetivo de elaborar proposta do Plano Nacional de Enfrentamento ao Tráfico de Pessoas - PNETP". Dispondo em seu artigo 3으 a respeito dos princípios e diretrizes quando determian que:

Art. 3 São princípios norteadores da Política Nacional de Enfrentamento ao Tráfico de Pessoas: 
I - respeito à dignidade da pessoa humana;

II - não-discriminação por motivo de gênero, orientação sexual, origem étnica ou social, procedência, nacionalidade, atuação profissional, raça, religião, faixa etária, situação migratória ou outro status;

III - proteção e assistência integral às vítimas diretas e indiretas, independentemente de nacionalidade e de colaboração em processos judiciais;

IV - promoção e garantia da cidadania e dos direitos humanos;

V - respeito a tratados e convenções internacionais de direitos humanos;

VI - universalidade, indivisibilidade e interdependência dos direitos humanos; e

VII - transversalidade das dimensões de gênero, orientação sexual, origem étnica ou social, procedência, raça e faixa etária nas políticas públicas.

Parágrafo único. A Política Nacional de Enfrentamento ao Tráfico de Pessoas observará os princípios da proteção integral da criança e do adolescente.

Sendo assim, é possível perceber que o Decreto acima citado implica em inúmeras "políticas públicas voltadas ao combate do tráfico internacional de pessoas, com diretrizes específicas assentadas no seguinte tripé: prevenção; repressão/reponsabilização e; assistência/proteção às vítimas" (Schulze, 2013).

O tráfico de pessoas, normalmente, é pro- movido com dois objetivos: a exploração sexual ou o trabalho escravo. Motivo pelo qual, de uma forma geral, as vítimas são pessoas com pouca instrução e de fácil manipulação que, diante de propostas convidativas relativas ao exercício de determinada atividade em outro país, diversa da que realmente irá exercer, cedem aos apelos intencionais dos traficantes. A situação é agravada nas regiões mais carentes, onde não raras vezes, os próprios pais incentivam seus filhos a aceitarem propostas de empregos que mascaram a exploração sexual da vítima. Assim, crianças são aliciadas para a prática de futebol no exterior; para ser modelo em agências renomadas, entre outras formas de aliciamento.

\subsection{O tráfico internacional para a explora- ção sexual}

O problema do tráfico internacional de pessoas com a finalidade de exploração sexual é antigo, no entanto, atualmente assumiu uma nova roupagem com formas modernas de escravidão, a qual se estendeu por toda a história, mas que, no mundo democrático acreditava-se extinto. Porém, devido à inércia do Poder Público, essa espécie de tráfico se desenvolveu livremente por muito tempo, e com isso, aperfeiçoou suas técnicas e procedimentos que foram consideravelmente auxiliados pelo avanço tecnológico.

A jurisprudência pátria assim se manifesta com relação ao tráfico humano: 
PENAL. APELAÇÃO CRIMINAL DA DEFESA. TRÁFICO INTERNACIONAL DE PESSOAS PARA EXPLORAÇÃO SEXUAL (ART. 231 DO CP). PRESCRIÇÃO. INCORRÊNCIA. AJUDA FINANCEIRA E DIRECIONAMENTO AO LOCAL DE PROSTITUIÇÃO. COMPROVAÇÃO DA MATERIALIDADE E DA AUTORIA DELITIVAS. CONCURSO FORMAL AFASTADO. APELO PARCIALMENTE PROVIDO. 1. Não há falar em prescrição quando entre a data do recebimento da denúncia e a de publicação da sentença transcorreu 01(um) ano, 11 (onze) meses e 02 (dois) dias, considerado o período de suspensão do processo, nos termos do art. 366 do CPP, com a novel redação da Lei 9271/96. 2. Com o fito de preservar a dignidade da pessoa e de coibir condutas que perpetuem a exploração sexual, tipifica o art.231 do CP as condutas de promover ou facilitar a saída de pessoas do Brasil ao Exterior, destinadas à prostituição. 3. Comprovada a ajuda financeira da apelante, assim como o direcionamento ao local onde a vítima se dedicaria à prostituição, evidencia-se a configuração da conduta "facilitar" do tipo penal em comento. 4. As declarações da vítima neste tipo de delito possuem valor probante fundamental, vez que são fonte direta de informação de como os fatos ocorreram. 5. Presente o tráfico de pessoas, ainda que a vítima houvesse consentido com a exploração sexual, sua vontade seria irrelevante para afastar a conduta delitiva. 6 . $O$ conjunto probatório é firme no sentido de que a ré contribuiu diretamente para o tráfico da vítima à cidade de Bilbao. To- davia, inexistem quaisquer elementos a demonstrar que, além da vítima mencionada na denúncia, a apelante teria auxiliado outras mulheres. Deve, portanto, ser afastado o concurso formal e, por conseguinte, a pena definitiva passa a ser de 03 (três) anos e 01 (um) mês de reclusão. 7. Consoante preceituado no artigo 59, IV, do Código Penal e presentes, no caso concreto, os requisitos do artigo 44 do mesmo diploma legal, é possível a substituição da pena privativa de liberdade por duas restritivas de direitos, a serem definidas e aplicadas pelo juízo da execução penal. 8 . Apelação da defesa parcialmente provida. (TRF 5a Região, ACR 200183000075120, Relator Desembargador Federal Marcelo Navarro, Terceira Turma, j. 15/03/2012, DJE 20/03/2012, p. 119).

Exclusivamente no que se refere ao crime de tráfico internacional de pessoa para fim de exploração sexual, a pena se diferencia da previsão anterior, pois atualmente a pena de multa somente é aplicada quando identificada a conduta contida no artigo 231 , § 3 ㅇ do Código Penal, onde: "Se o crime é cometido com o fim de obter vantagem econômica, aplica-se também multa". Ainda que não se possa pensar em crime de exploração sexual sem o intuito de vantagem econômica.

Também foram inclusas várias condutas que anteriormente não tinham previsão, tais como as que constam no $\S 1$ 을 do artigo 231 do Código Penal, onde: “§ 1ㅇIncorre na mesma pena aquele que agenciar, aliciar ou com- 
prar a pessoa traficada, assim como, tendo conhecimento dessa condição, transportá-la, transferi-la ou alojá-la".

Sendo que nestas três últimas situações o agente precisa ter conhecimento da condição de pessoa traficada.

Conforme explica Cristiane de Paula:

Uma pessoa pode viajar por vontade própria para outro local em seu próprio país ou no exterior e posteriormente cair no estado de servidão involuntária. 0 que constitui tráfico não é a movimentação dessa pessoa para o novo local, mas a força, a fraude e a coação a que essa pessoa é submetida para realizar um serviço para o patrão ou permanecer a seu serviço. Tais elementos definem o tráfico no uso moderno do termo. A pessoa que cai na armadilha do serviço forçado depois de haver migrado, de início voluntariamente, ou de haver aceito um emprego igualmente de sua própria vontade, ainda assim, é considerada vítima do tráfico (Dassie Leite, 2007).

Com relação ao crime de tráfico interno de pessoa para fim de exploração sexual, este com previsão no caput do artigo 231-A, teve a redução da pena com a nova Lei, a qual passou de três a oito anos para dois a seis anos. Assim, de acordo com o princípio da retroatividade da Lei mais benéfica inerente ao direito penal, todos que praticaram o crime de tráfico interno de pessoas, ainda que se encontrem cumprindo penas, receberão os benefícios por essa nova previsão reducionista.

Jaqueline Leite, coordenadora Geral do CHAME-Centro Humanitário de Apoio à MulherONG, citada por Cristiane de Paula, em seu artigo intitulado "o outro lado do turismo", ressalta o fato de que "o fenômeno do turismo sexual não é uma característica do Brasil ou de países do terceiro mundo, mas do sistema de dominação patriarcal que ainda rege grande parte do mundo" (Dassie Leite, 2007).

Esclarece ainda a autora acima citada que, não há dúvidas de que a maior parte de exploração consiste numa relação que ocorre entre países do "primeiro" e "terceiro" mundo e, além de não haver qualquer respeito aos direitos humanos, até pelo fato de acreditar que nos países subdesenvolvidos há permissão para qualquer tipo de exploração sem limites e leis que possam punir tais práticas.

Jaqueline Leite também afirma que:

(...) turismo sexual é uma indústria extremamente rentável e, ao mesmo tempo, sem escrúpulos quanto ao respeito à muIher e à dignidade humana. É destacada a posição do governo brasileiro, que a partir da década de 70 passou a investir muito na estrutura política do país e veiculou uma série de propagandas e vinhetas feitas com o objetivo de insinuar a sensua- 
lidade e beleza da mulher brasileira. A estratégia foi considerada um forte componente para o turismo, mas visava indireta e disfarçadamente o lucrativo turismo sexual (Dassie Leite, 2007).

Não há dúvidas de que o tipo penal brasileiro, que sanciona a exploração sexual possui, sempre, a intenção de lucro. Motivo pelo qual, essa espécie de crime foi identificada pela ONU como uma das modalidades criminosa mais lucrativa no mundo, ficando atrás somente do tráfico de drogas e de armas.

\subsection{O Tráfico internacional para o trabalho escravo}

A pobreza é o principal fator para os inúmeros casos de vítimas traficadas para fins de trabalho escravizado, pois a abordagem das com pessoas humildes é muito fácil, em geral, estas possuem instrução precária, e se apresentam bastantes vulneráveis às propostas de emprego mais irreais, sendo facilmente ludibriadas e levadas para verdadeiros covis nos quais são exploradas, maltratadas e usadas. Independentemente de o tráfico abastecer a mão de obra nacional ou internacional, pois a esperança de uma meIhora de vida faz com que a pessoa se torne uma vítima em potencial.

Nesse sentido, Felipe Pinheiro Mendes ressalta que:

Um importante ponto levantado pela Secretaria Nacional de Justiça é o referente a um suposto "papel social" desempenhado pelos migrantes ilegais. Conforme tal estudo, a ausência de direitos trabalhistas que resguardem a pessoa traficada permite a asseveração das atividades desempenhadas e redução, se não retenção, dos salários, como também evita que os trabaIhadores venham a se associarem aos sindicatos, inibindo possíveis oposições aos empregadores e facilitando a sujeição às condições impostas por estes, acarretando, assim, o aumento da produção com uma redução nos custos (Mendes, 2012).

Por outro lado, no que se refere ao tráfico internacional, é possível observar que os frutos do trabalho de uma pessoa traficada contribuem com os impostos do país estrangeiro no qual se encontra, sem que a mesma tenha qualquer direito às garantias sociais oferecidas por estes países.

Joana Azevedo da Costa faz importante associação entre a imigração ilegal e o tráfico de pessoas afirmando que inicialmente se dá a imigração ilegal e:

Assim sendo, ao investigar casos de tráfico de pessoas, pode ser por vezes necessário recorrer às medidas instituídas para o combate à imigração ilegal. É imprescindível, no entanto, que os profissionais que investigam os casos de auxilio à imigração ilegal (re)conheçam o crime do tráfico de pessoas, sob pena de se correr o risco de tratar um caso de tráfico como se fosse um caso de auxilio à imigração ilegal o que pode acarretar graves consequências para a vítima (Costa, 2011). 
Vale citar a reportagem do Jornal Correio Braziliense com relação a uma quadrilha de tráfico de pessoas que foi desarticulada pela Polícia Federal no mês de maio desse ano:

Uma quadrilha de tráfico internacional de pessoas foi desarticulada nesta quarta-feira (15/5) pela Operação Liberdade da Polícia Federal (PF). O grupo era formado por estrangeiros e trazia pessoas de Bangladesh para fins de trabalho escravo no Distrito Federal. De acordo com informações da PF, os componentes da quadrilha também eram bengalis e aliciavam conterrâneos com falsas promessas de salários altos. Eles cobravam até US\$ 10 mil pela imigração ilegal. As vítimas entravam no Brasil por rotas ilegais via Peru, Guiana Inglesa e Bolívia. Os agentes da polícia ainda fazem buscas nas residências dos investigados e nos alojamentos dos estrangeiros (Correio Braziliense, 2013).

Os artigos 206 e 207 do Código Penal são os únicos dispositivos nos quais se destaca uma preocupação do legislador com a prática do tráfico. Contudo, o artigo 206 está limitado aos casos onde há fraude, ou seja, o crime disposto nesse artigo não alcança o objetivo da Política Nacional adotada no Brasil, já que, de acordo com a mesma o tráfico de pessoas ocorre mesmo havendo a anuência da vítima, mas se esta concorda e não resta configurada a aliciação, não é possível sustentar a consumação do crime de aliciamento com a finalidade de emigração, previsto no citado artigo 206, demonstrando não ser tal dispositivo abrangente o suficiente para coibir a prática do tráfico.
Conforme as afirmações de alguns doutrinadores, entre eles, Julio Fabbrini Mirabete citado por Felipe Pinheiro Mendes, a palavra "trabalhadores", da forma como se encontra nos artigos 206 e 207, fez com que a doutrina a interpretação da doutrina se dê no sentido de que "apenas o recrutamento ou aliciamento de um número plural de trabaIhadores (mínimo 3) poderá caracterizar a consumação desses crimes, o que restringe ainda mais o âmbito de proteção das vítimas do tráfico" (Mirabete apud Mendes, 2013).

Rogério Greco ressalta que os tipos penais previstos nos artigos 206 e 207 do Código Penal brasileiro somente alcançam "o mero aliciamento e recrutamento, com o intuito de proteger tão somente a organização do trabalho, o interesse do Estado em manter seus trabalhadores em território nacional e em suas próprias regiões" (Greco, 2009, p. 312). Assim dispõem os artigos citados pelo autor:

Aliciamento para o fim de emigração

Art. 206 - Recrutar trabalhadores, mediante fraude, com o fim de levá-los para território estrangeiro.

Pena - detenção, de 1 (um) a 3 (três) anos e multa.

Aliciamento de trabalhadores de um local para outro do território nacional.

Art. 207 - Aliciar trabalhadores, com o fim 
de levá-los de uma para outra localidade do território nacional:

Pena - detenção de um a três anos, e multa.

$\S 1$ 을 Incorre na mesma pena quem recrutar trabalhadores fora da localidade de execução do trabalho, dentro do território nacional, mediante fraude ou cobrança de qualquer quantia do trabalhador, ou, ainda, não assegurar condições do seu retorno ao local de origem.

$\S 2$ ㅇ A pena é aumentada de um sexto a um terço se a vítima é menor de dezoito anos, idosa, gestante, indígena ou portadora de deficiência física ou mental.

Felipe Pinheiro Mendes chama atenção para o fato de que nesse contexto:

Falta, portanto, o caráter protetor do trabalhador como ser humano, como alguém que ao ser aliciado, mediante os meios expostos no art. 20 da política nacional de enfrentamento ao tráfico de pessoas, passa a ter cerceado seus direitos fundamentais. Com efeito, é preciso que se puna de forma mais severa os que praticam tal ato inegavelmente antijurídico, e que, por uma omissão legislativa permanece atípico. Nesse sentido, enquanto não se promove uma reforma legal, resta buscar a punição pela prática de crimes conexos ao tráfico, como os previstos nos artigos 148 (sequestro e cárcere privado) e 149 (redução a condição análoga a deescravo) do CPB (Mendes, 2012).
Assim, a criação de um dispositivo legal que promova punição eficiente para o tráfico de pessoas, com previsão de, pelo menos, dos mais prováveis meios para sua execução, assim como, as suas finalidades é de suma importância para a eficácia no combate a essa espécie de crime. Portanto, afirma Felipe Pinheiro Mendes que "a aplicação de um texto semelhante ao da Política Nacional de Enfrentamento ao Tráfico de Pessoas seria o ideal para que se constituísse a tipicidade do tráfico, atribuindo a este, definitivamente, o caráter de crime" (Mendes, 2013).

\section{A DIFICULDADE NA DETECÇÃO DO CRIME DE TRÁFICO DE PESSOAS}

Devido ao crime de tráfico ser bastante organizado a investigação e a comprovação do mesmo apresentam grandes dificuldades.

Quanto ao processo criminal que se refere ao crime de tráfico internacional de seres humanos, vale observar que o mesmo consiste nas dificuldades quanto à obtenção de provas, considerando-se que a rede criminosa normalmente é organizada e mantém diversos contatos com outros países, motivo pelo qual requer uma atuação articulada dos agentes.

Existem vários aspectos que dificultam a atuação contra essa espécie de crime, destacando Clenio Jair Schulze que:

(...) a execução de mandados de prisão em vários lugares do mundo, com variação de 
fuso-horário, além da diversidade de legislação nos Estados de origem e de destino da vítima. (...) importantes meios de prova: a interceptação telefônica; a filmagem do embarque da vítima - geralmente acompanhada do agente ativo do crime; o auxílio direito entre os representantes dos órgãos de combate, nos termos fixados na Convenção de Palermo, dispensando o uso de cartas rogatórias (Schulze, 2013).

Joana Azevedo da Costa afirma que entre as dificuldades se encontra:

A complexidade do local do crime que frequentemente se distribui por diferentes espaços; A dificuldade em obter o depoimento das vitimas que na maior parte das vezes é inconsistente e confuso, dada a sua condição física e psicológica diminuída; O fato da prova testemunhal ser muito difícil de lograr devido ao forte receio em depor contra os traficantes de índole reconhecidamente perigosa. E finalmente a natureza do crime altamente organizado, muitas vezes com agentes do crime infiltrados nas próprias forças policiais, funcionários dos serviços de estrangeiros e fronteiras e restantes operadores forenses (Costa, 2011).

\section{CONCLUSÃO}

Pode-se concluir que o combate ao tráfico internacional de pessoas deve envolver não somente os entes públicos, mas sim toda a sociedade civil, a fim de implementar a prevenção e a repressão aos crimes.
O tráfico de seres humanos encontra-se inegavelmente à miséria e exploração dos países considerados de terceiro mundo.

As pessoas de baixo poder aquisitivo são presas fáceis do tráfico, pois estas estão sempre buscando condições de vida mais dignas. Várias pessoas saem do país de origem de forma espontânea ou sob a influência dos aliciadores, que fazem promessas falsas, de uma realidade que não existe, deparando-se logo com a desilusão de serem submetidas a trabalhos forçados, na maioria das vezes em condições subumanas, arriscados, além de terem a liberdade cerceada ficando totalmente à mercê da exploração econômica dos empresários inescrupulosos.

Então, o tráfico de seres humanos não está restrito apenas à exploração sexual comercial, pois o trabalho escravo também é uma forte tendência para o destino das pessoas traficadas.

A questão do tráfico de pessoas para fins de exploração sexual recai especialmente sobre as mulheres, devido até mesmo a uma questão cultural. Então, as principais causas que facilitam o tráfico de pessoas são os fatores econômico-social e cultural.

Entretanto, apesar da dificuldade das comunidades mundiais em detectar a verdadeira causa do tráfico, bem como em admitir pontos relevantes que ferem princípios morais, vários avanços tiveram importantes conquis- 
tas no que se refere à proteção internacional dos direitos humanos das mulheres com inúmeros procedimentos eficientes de combate ao tráfico de pessoas.

Somente nas últimas décadas é que a questão do tráfico internacional de pessoas passou a merecer especial atenção das comunidades nacionais e internacionais.

Vale observar que todo tipo de ilegalidades, entre as quais se encontram a atividade do narcotráfico, da lavagem de dinheiro, do jogo do bicho, os materiais de contrabandos, o tráfico humano, entre outros são condutas recriminadas mundialmente cujo foco das autoridades de todas as nações está voltado para promover a eliminação das mesmas.

A criminalidade é um produto da sociedade, portanto, sua eliminação tem fundamentação ns bases dessa mesma sociedade. Então, o tráfico de pessoas está enraizado a questões sócio-culturais nas quais se insere a realidade política e social.

\section{REFERÊNCIAS}

Baganha, I. (2008). Tráfico de Mulheres em Portugal para fins de exploração sexual. Coleção estudos do Género, Comissão para a Cidadania e Igualdade de Género, Lisboa.

Brasil. Legislação. Disponível em <www.planalto.gov.br.> Acesso em 08 jun 2013.
Correio Braziliense. PF desarticula quadrilha de tráfico internacional para trabalho escravo. (15/05/2013). Disponível em <http:// www.correiobraziliense.com.br/app/noticia/cidades/2013/05/15/interna_cidadesdf,366076/pf-desarticula-quadrilha-de-trafico-internacional-para-trabalho-escravo. shtml>. Acesso em 14 jun 2013.

Costa, J. Azevedo da. (2011). Tráfico de Seres Humanos. (2011). Disponível em <http:// www.verbojuridico.com/doutrina/2011/joanacosta_traficosereshumanos.pdf.> Acesso em 15 jun, 2013.

Dassie Leite, A. P. (2007). O grupo terapeutico fonoaudiológico como possibilidade de intervencao junto a criancas disfonicas: análice de um proceso. Campinas.

Diniz, M. H. (2005). Curso de Direito Civil Brasileiro. Direito de Família. 20. ed. São Paulo: Saraiva.

Ferreira, L. C. M. (2007). Seguridade Social e Direitos Humanos. São Paulo: LTr.

Fleiner, T. (2003). O que são Direitos Humanos? (Trad.) de Andressa Cunha Curry. São Paulo: Max Limonad.

Greco, R. (2009). Curso de Direito Penal. v. 3. Rio de Janeiro: Impetus.

Kant, I. (2004). Fundamentação da metafísica dos costumes e outros escritos. (Trad.) Leopoldo Holzbach. São Paulo: Martin Claret. 
Mendes, F. P. (2012). O tráfico de pessoas e a exploração da força de trabalho. Jus $\mathrm{Na}$ vigandi. Disponível em <http://jus.com.br/ revista/texto/23236. Acesso em 10 jun 2013.

Moraes, A. de. (2003). Constituição do Brasil interpretada e legislação constitucional. 2 ed. São Paulo: Atlas.

Piovesan, F. (2002). Direitos humanos e o direito constitucional internacional. 5. ed. São Paulo: Max Limonad.

Piovesan, F. (2005). Direitos humanos, o princípio da dignidade humana e a Constituição brasileira de 1988. Revista dos Tribunais, 94(833), 41-55. São Paulo, março.

Santos, B., Gomes, C., Duarte, M., Baganha, M., Sarlet, I. W. (2006). Dignidade da Pessoa Humana e Direitos Fundamentais. Porto Alegre: Livraria do Advogado.

Schulze, C. J. (2013). O princípio da dignidade e o tráfico internacional de seres humanos. Jus Navigandi. Disponível em: <http://jus. com.br/revista/texto/23456/o-principio-da-dignidade-e-o-trafico-internacional-de-seres-humanos.> Acesso em 05 jun.
Smith, A. do Socorro Pantoja de Oliveira. A definição do crime de tráfico de pessoas para exploração sexual após a promulgação da Lei no 12.015/09. Jus Navigandi. Disponível em: <http://jus.com.br/revista/texto/23922>. Acesso em 10 jun 2013.

Tirado Acero, M. (2010). Comercio sexual. Una mirada desde la sociología jurídica. IIDS-FEFSA Lima-Bogotá.

Tirado Acero, M. Implicações do trabalho sexual como atividade legalmente reconhecida: Um acercamento ao trabalho sexual desde suas dimensões sociológicas e econômicas. Prolegómenos Derechos y Valores, XIV(27). Universidad Militar Nueva Granada. Disponível em: http://www.umng.edu.co/ documents/63968/71198/tnn_15.+articulo+15+rev+27.pdf

Vicente, P., Alexandrino, M. (2010). Direito Constitucional Descomplicado. 5. ed., rev. e atual. Rio de Janeiro: Forense. São Paulo: Método. 